\title{
Cohesive Errors in Writing among ESL Pre-Service Teachers
}

\author{
Lisa S. L. Kwan ${ }^{1} \&$ Melor Md Yunus ${ }^{1}$ \\ ${ }^{1}$ Faculty of Education, Universiti Kebangsaan Malaysia (UKM), Bangi, Selangor, Malaysia \\ Correspondence: Lisa Kwan Su Li, Faculty of Education, Universiti Kebangsaan Malaysia (UKM), 43600 Bangi, \\ Selangor, Malaysia. Tel: 60-169-121-965. E-mail: lisakwan24@gmail.com
}

Received: June 24, 2014 Accepted: July 31, 2014 Online Published: October 23, 2014

doi:10.5539/elt.v7n11p130 URL: http://dx.doi.org/10.5539/elt.v7n11p130

\begin{abstract}
Writing is a complex skill and one of the most difficult to master. A teacher's weak writing skills may negatively influence their students. Therefore, reinforcing teacher education by first determining pre-service teachers' writing weaknesses is imperative. This mixed-methods error analysis study aims to examine the cohesive errors in the writing of English as a Second Language (ESL) pre-service teachers of differing language proficiency levels-Medium and High-level, as indicated by the band levels achieved in the Malaysian University English Test (MUET). 200-word narrative essays were collected from 30 final-year ESL pre-service teachers from UKM via email. The study found that the Medium-level pre-service teachers made the most errors in lexical cohesion, reference and conjunction cohesion categories. However, High-level pre-service teachers made more errors in lexical cohesion, ellipsis and reference. Collocation proved the most difficult form of cohesion for both groups of pre-service teachers, while High-level pre-service teachers made more errors in ellipsis than the Medium-level pre-service teachers. Nevertheless, this still indicates that the pre-service teachers' overall mastery of cohesive writing is insufficient. Therefore, the teaching of these cohesive devices should be further fortified in the linguistic courses undertaken by ESL pre-service teachers to ensure that they are well-equipped in all aspects of cohesive writing.
\end{abstract}

Keywords: cohesive errors, error analysis, second language learning, pre-service teachers, ESL, writing skills

\section{Introduction}

The Malaysian government has voiced a concern over the poor English language proficiency of the English teachers in the country. After the initial review prior to the Malaysian Education Blueprint (MEB) 2013-2025, Datuk Dr. Khair Mohamad Yusof, Education Ministry deputy director-general said in the Star newspaper that two-thirds of English teachers in Malaysia did not meet the proficiency level (Jalleh, 2012). This means that about 47,000 teachers out of the 70,000 teachers who sat for the Cambridge Placement Test (CPT) did not possess the adequate level of proficiency as English teachers who teach the language. As a result of the outcome of the CPT, the government has initiated various efforts for the upskilling of teachers which were incorporated as part of the shifts in the Malaysian Education Blueprint 2013-2025.

However, these efforts are to upskill current serving teachers in the field whose language proficiency is inadequate. The researchers believe that much can be done in the studying years of a pre-service teacher in higher education institutions before going out into the field. A teacher, who is to teach her students competency in the language needs to first be competent in the language herself (or himself), in all language skills and beyond. This includes writing skills, which are important for real-life and authentic communication (Lowry, Curtis, \& Lowry, 2004).

As an English as a Second Language (ESL) learner, writing is a complex skill that is one of the most difficult to master among the four basic language skills. Research has been focused on enhancing writing skills, including through the incorporation of online tools and web technology (Jalaluddin, Yamat, \& Yunus, 2013; Said et al., 2013; Yunus, Salehi, \& Chen, 2012; Yunus, Salehi, \& Nordin, 2012). Students' poor writing skills have been attributed to various factors, one of which is the teacher's weakness in that area as well. In the US, native-speaker teachers were said to be "weak writers" due to the lack of writing classes during pre-service teacher education (Anon., 2003, p. 4). This indicates that without proper emphasis or instruction in writing during the teacher education stage, even natives of the language will be weak in the skill. If even natives of the language can be weak in writing skills, what more ESL teachers and pre-service teachers in Malaysia who are 
often still ESL learners themselves?

This is of utmost importance and concern as teachers who are not proficient in the language may cause negative language error transfer to students (Nel \& Müller, 2010). A review of literature discovered that teaching factors do affect student outcomes (Kyriakides, Christoforou, \& Charalambous, 2013), implicating that a teacher's actions and competence have an influence on their students' achievement. This indicates that teachers' inadequacy in writing skills may affect students' writing as well by transferring common errors made by the teacher to students' writing. In the meantime, studies have suggested that writing quality is highly related to cohesion and coherence (DeVillez, 2003). Hence, it is also relevant and important to investigate these aspects in teachers' writing as an indication of their writing proficiency and quality. While there have been studies done on students' cohesion and use of cohesive devices in writing (Crossley \& McNamara, 2010a; McNamara, Crossley, \& McCarthy, 2010; Tangkiengsirisin, 2010), little research has been done on cohesive errors (Sadighi \& Heydari, 2012). However, Sadighi and Heydari's (2012) study did find that students of differing levels of proficiency made more errors in different types of cohesion devices. The researchers believe that the study of the cohesive errors made by learners, besides the use of cohesive devices, is equally important as it provides tangible evidences of what the learner has or has not mastered, and what is lacking in their linguistic development (Corder, 1967), especially in the aspect of cohesion in writing. In addition, to the knowledge of the researchers, there are no studies done that look into the cohesive errors produced by Malaysian ESL pre-service teachers in writing.

Efforts in improving teacher quality especially in writing skills need to be gradual and systematic rather than impulsive in order to be effective in the long-term. A better understanding of the weaknesses in cohesive writing is first required to inform subsequent steps to improve ESL pre-service teachers' written language proficiency. In order to obtain that, error analysis needs to be performed to identify frequent cohesive errors plaguing ESL pre-service teachers. This study aims to examine the most frequent cohesive errors produced by ESL pre-service teachers of different proficiency levels, and explore the similarities and differences between them; from which implications for teacher education may be drawn.

\section{Literature Review}

\subsection{Cohesion in Second Language Writing}

Halliday and Hasan's (1976) seminal work drew attention to cohesion in writing besides providing a comprehensive and systematic analysis of cohesion in text. Cohesion has been regarded as highly important in the organisation of text. Halliday and Hasan (1976) explain that cohesion is a semantic concept related to meaning within the text, rather than a structural one. A cohesive text is when "the interpretation of some element in the discourse is dependent on another" (Halliday \& Hassan, 1976, p. 5). This dependence on other elements within the discourse is realised through cohesive ties that ultimately make the text cohesive. These elements that Halliday and Hasan (1976) refer to are cohesive devices, which are responsible for forming the semantic ties within the text that brings the entire text together.

Other researchers and linguists later built upon the foundation laid by Halliday and Hasan (1976). Grabe (1985) also suggested linguistic features in the text that account for its cohesiveness, while Hinkel (2003, p. 279) conceptualized cohesion as "the connectivity of ideas in discourse and sentences to one another in text, thus creating the flow of information in a unified way". Hence, from these definitions, cohesion can be said to be the connectivity and flow within the text that are established through the use of devices that cause the elements within the text to be inter-related and inter-dependent.

\subsection{Halliday and Hasan's Cohesion Taxonomy}

Research in the field of cohesion in writing have prominently referred to and adhered to Halliday and Hasan's (1976) Cohesion Taxonomy. Various studies employing the taxonomy demonstrate the success and value of the taxonomy with regards to research on cohesion and even cohesive errors (Huang, 2005; Na, 2011; Ong, 2011). Similarly, the present study chose to adhere to Halliday and Hasan's (1976) Cohesion Taxonomy as it offers the most comprehensive and systematic analysis of cohesion ties in English. Halliday and Hasan (1976) defined cohesion as what occurs when the comprehension of one element is dependent on another within the text.

Halliday and Hasan (1976) identified five categories of cohesion: reference, substitution, ellipsis, conjunction and lexical cohesion. The first three types fall under the category of grammatical cohesion. Reference uses personal pronouns, demonstratives and comparatives to establish a cohesive relation between the cohesive item and its antecedent. Substitution refers to the replacement of an item by another, while ellipsis refers to omission of an item; both occur at nominal, verbal and clausal levels. Conjunctive cohesion lies on the borderline between 
grammatical cohesion and lexical cohesion, and is established by the use of conjunctions like thus, because, and so. Conjunctive cohesion can occur within and between sentences. Lexical cohesion on the other hand refers to relationships between any lexical item and some previously occurring lexical item in the text quite independently of the grammatical category of the items in question. Cohesion on a lexical level may be established through the repetition of words, synonymy or antonymy. Apart from that, hyponymy, or the use of superordinates of words, and collocation, which is the linking of lexical items that often co-occur in a particular context of text, are also forms of lexical cohesion. A summary of Halliday and Hasan's (1976) Cohesion Taxonomy including all its subcategories can be seen below:

Table 1. Halliday and Hasan's (1976) cohesion taxonomy

\begin{tabular}{ll}
\hline Category & Sub-category \\
\hline Reference & personal \\
& demonstrative \\
& comparative \\
Substitution & nominal \\
& verbal \\
clausal & nominal \\
Ellipsis & verbal \\
& clausal \\
Conjunction & - \\
Lexical cohesion & repetition \\
& synonymy \\
& antonymy \\
& hyponymy \\
& collocation \\
\hline
\end{tabular}

\subsection{Studies on Cohesion}

Quite a number of studies have presented evidence of a significant relationship between cohesive ties and writing quality (Liu \& Braine, 2005; Song \& Xia, 2002). Liu and Braine (2005) examined argumentative writing of Chinese undergraduate students and found that the use of certain cohesive devices was a factor for high quality in writing. Recent studies also found positive correlations between the number of cohesive ties and writing quality, albeit a weak one, whereby they were better predictors of students' quality of writing (Zhang, 2010). In contrast, Castro (2004) reported no difference in terms of cohesive density in good and poor compositions (Castro, 2004). Thus, even the use of cohesive devices as higher quality writing has not been truly substantiated either.

The relationship between cohesion and proficiency is yet another hazy one. In another study investigating writing proficiency of Hong Kong high school students by Crossley and McNamara (2010b), second language writers who are considered highly proficient did not necessarily produce essays that were more cohesive. Instead, they appeared to demonstrate more "linguistic sophistication" by employing a wider range of words that were less familiar and less frequently used $(2010 \mathrm{~b}, \mathrm{p} .17)$. This was said to be probably due to the "reverse cohesion effect" whereby there is an inverse relationship between writer's proficiency and cohesiveness. Studies in reading had discovered that low-knowledge readers benefit more from cohesive texts, while high knowledge readers from less-cohesive texts. More proficient writers, then, in assuming other high knowledge readers, may produce less-cohesive texts (Crossley \& McNamara, 2010b). Hence, cohesive writing may not necessarily be an indicator of higher writing proficiency.

Comparison studies between different groups of learners were also conducted to investigate similarities and differences in the use of cohesion in writing. $\mathrm{Na}$ (2011) attempted to compare the cohesive devices and cohesive 
errors of native and non-native speakers. In comparing the Korean and American university students, the non-native speakers, or Korean students, were found to have used more cohesive devices than the natives, or American students. The results of the study indicated a significant overuse of cohesive devices, which are not necessarily applied accurately or appropriately in writing (Na, 2011). With Chinese EFL learners in Singapore, Ong (2011) examined the students' expository writing and found that reference cohesion, conjunction and lexical cohesion posed greatest difficulty for the students. However, results also showed redundant and inaccurate use of cohesive devices, lending more support and weight for Na's (2011) study. In addition, Huang's (2005) study found that cohesive errors was one of the top three most frequent errors besides grammar and lexical errors by Chinese learners.

The purpose of the study was to examine the cohesive errors in written productions of ESL pre-service teachers of differing levels of proficiency and compare them. Do ESL pre-service teachers face challenges in cohesive writing? What are the most frequent types of cohesive errors produced by ESL pre-service English teachers of different proficiency levels, and how are they similar or different? How does this influence the choices for program structure in teacher education? For a clearer understanding, the terms in the study are defined below.

\subsection{Definition of Terms}

"Cohesive errors" may be defined as "instances in which the writer provides an ambiguous or wrong tie/referent pair or fails to supply a complete tie/referent pair" (Huang, 2005). In this study, "cohesive errors" refer to the errors made under the five main categories and all the respective subcategories in Halliday and Hasan's (1976) Cohesion Taxonomy of cohesive devices. These cohesive errors are only in relation to written errors and not those made in speech. A "pre-service teacher" is a student in "an education major but has not yet completed training to be a teacher" (Glossary of Education, 2012). The present study refers to pre-service English teachers as those currently undergoing their Education program in the Teaching of English as a second language (TESL). The "English language proficiency level" is indicated by the Malaysian University English Test (MUET) band achievements of the pre-service English teachers. For the purpose of this study, the 3 levels of proficiency were categorised as follows: bands 1 and 2 are Low, bands 3 and 4 are Medium, and bands 5 and 6 are High. However, as TESL students and pre-service English teachers, the sample consisted of Medium and High English language proficiency-level pre-service teachersonly. In the context of Malaysia, ESL pre-service teachers are also ESL learners during the teacher education stage, and are viewed as such in this study.

\section{Method}

\subsection{Research Questions}

The study aimed to answer the following questions:

1) What are the most frequent cohesive errors produced by ESL pre-service teachers of different levels of proficiency?

2) What are the similarities and differences in the most frequent cohesive errors produced by ESL pre-service teachers of different levels of proficiency?

\subsection{Research Design}

The study used an error analysis design employing both quantitative and qualitative methods. The rationale behind selecting error analysis is because it is a systematic approach to examining errors by identifying and classifying them, which allows for problem areas in the aspect under study to be isolated and dealt with. By knowing which aspect of cohesion is most problematic for ESL pre-service teachers, what has been mastered and what has not can be identified (Corder, 1967), informing and enabling further action. In addition, understanding the errors and origins of errors will help highlight learners' difficulties in cohesive writing.

\subsection{Respondents}

The respondents consisted of 30 final-year ESL pre-service teachers of the Faculty of Education, UKM. They consist of 23 female ESL pre-service teachersand 7 male, making up for $76.7 \%$ and $23.3 \%$ respectively. Information on the pre-service teachers' MUET (Malaysian University English Test) band achievement was also obtained as a measure of their English language proficiency. As expected, all ESL pre-service teachers have a minimum achievement of band 4 and are at least competent users of the language (Politeknik Ungku Omar, 2013). Therefore, based on the definition of "English language proficiency level" provided in 2.4, only Medium (band 4) and High (bands 5 and 6) level proficiency pre-service teachers were involved in the study. There were 18 pre-service teachers $(60.0 \%)$ with medium-level English proficiency, and $12(40.0 \%)$ with high. 


\subsection{Instrumentation}

In order to conduct the error analysis, a sample of writing was required from the ESL pre-service teachers. Hence, they were asked to write (on a word processor) a 200-word narrative essay on one of the following three topics: 1) "An embarrassing experience", 2) "If I were a millionaire", and 3) "A thrilling experience in my life". A narrative essay was chosen because it is descriptive and typically sequential and thus should have more instances of cohesion and use of cohesive devices. Only the first 200 words of the essay were examined while the rest of the words were not taken into account to remove any bias, as the length of each essay returned varied.

\subsection{Data Collection}

The expression of the research purpose and instructions for writing the narrative essay were sent in a Word document to all 30 pre-service teachersvia email. However, they were not told what was investigated in the study to avoid raising the respondents' consciousness towards cohesion in their writing, and thus, avoid any bias. The respondents were requested to fill in the respondent profile which included their name, gender, program and year, MUET band achievement and their email address in case of need for contact. Instructions were given to choose one of the 3 topics provided and to write an essay of at least 200 words. The completed Word document essays were re-attached and returned to the researchers via email as well.

\subsection{Data Analysis}

The data were analysed quantitatively using descriptive statistics with frequency and percentages. The respondents were divided into blocks of Medium and High-level proficiency pre-service teachers. Referring to Halliday and Hassan's (1976) Cohesion Taxonomy, cohesive errors for all categories and subcategories made by each group of pre-service teachers were identified, and categorised. Since the focus was on cohesive errors only, grammatical and spelling errors in the essays were overlooked and discounted. The frequency of cohesive errors for each category and subcategory of cohesive devices was calculated and converted to percentages from the total number of cohesive errors made. All results were tabulated. The most frequent types of cohesive errors for both the Medium and High-level proficiency pre-service teachers were identified to answer the first research question. They were then compared between the two groups of students, and the similarities and differences between them were determined and explained using qualitative methods to answer the second research question. Respondents' scripts were coded Rs01, Rs02 and so forth.

\section{Results}

The cohesive errors made by the different proficiency-level ESL pre-service teachers were tabulated in order to determine the most frequent cohesive errors made by Medium and High-level proficiency pre-service teachers. The similarities and differences between the most frequent cohesive errors made by both groups were identified and discussed below.

\subsection{Most Frequent Cohesive Errors by Medium-Level Proficiency Pre-service Teachers}

The frequency and percentages of the cohesive errors made in the essays by the medium-level proficiency pre-service teachers were calculated and tabulated according to each category and subcategory in Halliday and Hasan's (1976) Cohesion Taxonomy. In the 18 scripts received, the medium-level proficiency pre-service teachers made a total of 68 cohesive errors.

The significantly highest percentage of cohesive errors was from the lexical cohesion category, with $83.82 \%$. From the $83.82 \%$ of lexical cohesion errors, a major portion is collocation errors $(77.19 \%)$. This could be because most ESL learners are unaware of certain collocation aspects of the words used and thus were used incorrectly in their essays. For example, one pre-service teacher had written: "We were having fun with student's night performance..." is incorrect as the phrasal verb have fun with the preposition with should be followed by a somebody (sb) and not a something (sth). One "has fun with sb" and not with an event, as was the case in this example. Errors of this type demonstrate the pre-service teachers' weak grasp of collocation or their unawareness of it.

Following the lexical cohesion errors are reference errors (14.71\%) of the personal and demonstrative subcategories. Looking at an example: "All of us read fairy tales...Not to mention the "happily ever after" connotation it brings", it is evident that this pre-service teacher had made an error in reference, where they, referring to the fairy tales mentioned earlier, should be used instead of $i t$. Such mistakes show the pre-service teachers' lack of mastery in this aspect. Following that, there was 1 error in conjunction (1.47\%). However, there were no errors found for the substitution and ellipsis categories. This is probably because the pre-service teachers do not use substitution and ellipsis cohesion in their writing and thus produce no errors. This is further discussed in a later section (5.1). The summary of the frequency and percentages of cohesive errors made by the 
medium-level proficiency pre-service teachers are below:

Table 2. Frequency and percentage of cohesive errors made by medium-level proficiency pre-service teachers

\begin{tabular}{|c|c|c|c|c|c|}
\hline $\begin{array}{l}\text { Cohesion } \\
\text { categories }\end{array}$ & $\begin{array}{l}\text { Number } \\
\text { of errors }\end{array}$ & $\begin{array}{l}\text { Percentage of } \\
\text { errors }(\%)\end{array}$ & $\begin{array}{l}\text { Cohesion } \\
\text { subcategories }\end{array}$ & $\begin{array}{l}\text { Number of } \\
\text { errors }\end{array}$ & $\begin{array}{l}\text { Percentage of } \\
\text { errors }(\%)\end{array}$ \\
\hline \multirow[t]{3}{*}{ Reference } & \multirow[t]{3}{*}{10} & \multirow[t]{3}{*}{14.71} & Personal & 6 & 60.00 \\
\hline & & & Demonstrative & 4 & 40.00 \\
\hline & & & Comparative & 0 & 0.00 \\
\hline \multirow[t]{3}{*}{ Substitution } & \multirow[t]{3}{*}{0} & \multirow[t]{3}{*}{0.00} & Nominal & 0 & 0.00 \\
\hline & & & Verbal & 0 & 0.00 \\
\hline & & & Clausal & 0 & 0.00 \\
\hline \multirow[t]{3}{*}{ Ellipsis } & \multirow[t]{3}{*}{0} & \multirow[t]{3}{*}{0.00} & Nominal & 0 & 0.00 \\
\hline & & & Verbal & 0 & 0.00 \\
\hline & & & Clausal & 0 & 0.00 \\
\hline Conjunction & 1 & 1.47 & Conjunction & 1 & 100.00 \\
\hline \multirow{5}{*}{$\begin{array}{l}\text { Lexical } \\
\text { cohesion }\end{array}$} & \multirow[t]{5}{*}{57} & \multirow[t]{5}{*}{83.82} & Repetition & 11 & 19.30 \\
\hline & & & Synonymy & 2 & 3.51 \\
\hline & & & Antonymy & 0 & 0.00 \\
\hline & & & Hyponymy & 0 & 0.00 \\
\hline & & & Collocation & 44 & 77.19 \\
\hline Total & 68 & 100.00 & & 68 & \\
\hline
\end{tabular}

Therefore, from the table above, the most frequent cohesive errors made by medium-level proficiency pre-service teachers are (1) Lexical Cohesion, particularly collocation, followed by (2) Reference and (3) Conjunction.

\subsection{Most Frequent Cohesive Errors by High-Level Proficiency Pre-Service Teachers}

The frequency and percentages of the cohesive errors made by the high-level proficiency pre-service teachers were calculated and tabulated according to each category and subcategory in Halliday and Hasan's (1976) Cohesion Taxonomy. A total of 24 cohesive errors were found in the 12 scripts. This significantly lower number of cohesive errors is expected as higher proficiency level pre-service teachers should produce fewer errors in their writing.

From Table 3 below, it can be seen that the highest percentage of cohesive errors are also of the lexical type (75.00\%) with collocation errors accounting for almost all of them (94.54\%) but one, which is a lexical repetition error (5.56\%). Even high-level proficiency pre-service teachers produced erroneous sentences such as, "I will use the money and send my parents to have a vacation in whatever places they like" and "...mini car which he would use to travel from one place in his castle from another" where one should "send $\mathrm{sb}$ on a vacation" and travel "from one place to another". This implies that, despite having a higher proficiency level, most of the pre-service teachersalso experience difficulty in the collocation aspect of certain words and used them incorrectly in their writing.

Following lexical cohesion errors are ellipsis (12.50\%), reference $(8.33 \%)$ and conjunction errors (4.17\%). Errors in ellipsis indicates that there was usage of ellipsis by high-level proficiency pre-service teachers in writing, albeit inaccurately. One example is "Just like when Beyonce sings 'If I were a boy'. Well, she can ' $t$ ", where it should be "she isn't" instead. Although this shows that high-level pre-service teachers are aware of the use of ellipsis in writing, they were unable to use it correctly. Besides that, no substitution were errors made. A summary of the frequency and percentage of cohesive errors made by high-level proficiency pre-service teachers is shown below: 
Table 3. Frequency and percentage of cohesive errors made by high-level proficiency pre-service teachers

\begin{tabular}{llllll}
\hline $\begin{array}{l}\text { Cohesion } \\
\text { categories }\end{array}$ & $\begin{array}{l}\text { Number } \\
\text { of errors }\end{array}$ & $\begin{array}{l}\text { Percentage } \\
\text { of errors (\%) }\end{array}$ & $\begin{array}{l}\text { Cohesion } \\
\text { subcategories }\end{array}$ & $\begin{array}{l}\text { Number } \\
\text { of errors }\end{array}$ & $\begin{array}{l}\text { Percentage } \\
\text { of errors (\%) }\end{array}$ \\
\hline Reference & 2 & 8.33 & $\begin{array}{l}\text { Personal } \\
\text { Demonstrative }\end{array}$ & 1 & 50.00 \\
& & & $\begin{array}{l}\text { Comparative } \\
\text { Nominal }\end{array}$ & 0 & 50.00 \\
Substitution & 0 & 0.00 & Verbal & 0 & 0.00 \\
& & & Clausal & 0 & 0.00 \\
& & & Nominal & 2 & 0.00 \\
Ellipsis & 3 & \multirow{2}{*}{12.50} & Verbal & 1 & 33.33 \\
& & & Clausal & 0 & 0.00 \\
Conjunction & 1 & 4.17 & Conjunction & 1 & 100.00 \\
Lexical & 18 & 75.00 & Repetition & 1 & 5.56 \\
cohesion & & & Synonymy & 0 & 0.00 \\
& & & Antonymy & 0 & 0.00 \\
& & & Hyponymy & 0 & 0.00 \\
Total & & & Collocation & 17 & 94.44 \\
\hline
\end{tabular}

Therefore, the most frequent cohesive errors made by high-level proficiency pre-service teachers are (1) Lexical Cohesion, especially collocation, followed by (2) Ellipsis and (3) Reference.

4.3 Similarities and Differences between Most Frequent Cohesive Errors Made by Medium and High-Level Proficiency Pre-Service Teachers

The most frequent cohesive errors made by medium-level proficiency pre-service teachersare (1) Lexical Cohesion, (2) Reference and (3) Conjunction, whereas for high-level proficiency pre-service teachers, it is (1) Lexical Cohesion, followed by (2) Ellipsis and (3) Reference.

For both groups of ESL pre-service teachers, lexical cohesion proved the most problematic. This category of cohesive errors contributed the most to the corpus of errors collected from their writing, with subcategory collocation errors the highest. This indicates that lexical cohesion, particularly collocation, has yet to be fully mastered by the pre-service English teachers. Medium-level proficiency students had trouble with phrasal and intransitive verbs. Certain phrasal verbs require the direct object to be positioned in the middle rather than at the end. An example of students' error: "And of course I will bring along my precious family to share my happiness" should accurately be "bring my precious family along" (Rs03). Similarly, "wailing" is an intransitive verb that does not require an object, which makes the sentence "They were talking in Tamil asking and wailing us to leave the campsite" (Rs01) inaccurate. This shows that the students are not familiar with collocation and rules for using these verbs.

However, both groups of pre-service teachers had major difficulty with phrasal verbs that take prepositions. These verbs require specific prepositions for specific meanings; otherwise, they are incorrect. For example, the verb "donate" needs to be followed by the preposition "to" and not any other preposition. The sentence "After that I want to donate my huge sum of money for charity" written by Rs03 therefore, is erroneous. The similarity between the medium and high-level proficiency pre-service teachers is that both produced numerous erroneous sentences of this particular type. Below are examples of students' errors:

Medium-level proficiency students

1) We could be so carried away with the feeling that we almost forget that life is not as easy and sweet as in fairy tales. (carried away by sth)

2) ...where there are a lot of beggars who ask money so that they can continue their life. (ask for sth) 
3) At the same time, she could not help feeling sorry to her boyfriend who was feeling unwell. (feel sorry for $\mathrm{sb}$ )

High-level proficiency 1) I have this habit of spending every bit of cash I have when I go for a shopping students spree. (go on a shopping spree)

2) Firstly, I would sponsor my whole family on a Europe tour! (sponsor sb/sth for)

3) Besides, I would like to invest the money on myself and my family so that I will have my own savings in the future. (invest in sth)

Therefore, the data indicates that both groups of medium and high-level proficiency pre-service teachers had the most difficulty in the aspect of collocation in writing. Regardless of the level of English language proficiency, collocation posed the biggest challenge to master and resulted in numerous errors of that particular type in their writing.

Besides collocation errors, ESL pre-service teachers made lexical repetition errors. However, the medium-level proficiency pre-service teachers produced more repetition errors than the high-level proficiency pre-service teachers. There was often an addition of linking verbs that was unnecessary and made the sentences incorrect. Examples of these errors made by the pre-service teachersare:

Medium-level 1) I always think of myself be in certain places like in the New York where I can go proficiency students shopping and experience new things.

2) ...I know the feeling when you are in need but there is nobody is there...

3) I still remember the incident was happened after my lunch break.

Reference error is one of the 3 most frequent cohesive errors made by the 2 groups of pre-service teachers. However, the number of reference errors made by the high-level proficiency pre-service teachers is small (2) and almost negligible. The medium-level proficiency pre-service teachers, on the other hand, made 10 errors in this category. They did not make errors of gender-sensitive pronoun references, but were either unclear or used incorrect pronouns altogether. Some examples of students' errors:

Medium-level proficiency students

1) A friend happened to know how to 'heal' this kind of sickness. They were talking in Tamil asking and wailing us to leave the campsite. (unspecified "they")

2) I tried to say it out loud several times to call for any serious thought I ever had about it. (unclear "it")

3) All of us read fairy tales...Not to mention the "happily ever after" connotation it brings. (they bring)

4) I feel a great pain whenever I see them especially the children. Most of them are not able to afford education for their children. (incorrect "them")

The types of reference errors made above imply that ESL pre-service teachers are rather careless when using reference cohesive devices, or are unaware of what they are referring to in preceding sentences. This might mean that medium-level proficiency pre-service teachers have not yet mastered references in cohesive writing.

One of the more evident differences in the most frequent cohesive errors made by medium and high-level proficiency pre-service teachers is ellipsis errors. While the medium-level proficiency pre-service teachers committed no ellipsis errors, the high-level ones made 3 errors, making it the second highest of the three most frequent cohesive error types for high-level proficiency pre-service teachers. Pre-service teachers appear to have a misconception of nominal and verbal ellipsis, and thus, have not mastered this cohesive device as well. The ellipsis errors made by students can be seen below:

High-level proficiency 1) Just like when Beyonce sings "If I were a boy". Well, she can't. (she isn't) students

2) One of four, I had the opportunity of a lifetime to visit Mexico for three weeks. (unclear)

3) ...I bet every single person in this world will raise their hands, so do I. (as will I)

However, the presence of ellipsis errors also signifies that there has been use of the ellipsis cohesion in high-level proficiency pre-service teachers' writing. On the other hand, it cannot be said that the medium-level proficiency pre-service teachers have mastered the ellipsis cohesive device as the absence of ellipsis errors in their writing is more likely due to no use of the device whatsoever. The medium-level pre-service teachers could be avoiding its use because it is difficult for them to employ in their writing. This is further discussed in the 
following section.

\section{Discussion}

In this section, we discuss the findings of the study in relation to the literature, as well as implications for teacher education, and the limitations of the study.

\subsection{Cohesive Errors by Medium and High-Level English Proficiency Pre-Service Teachers}

From the analysis of the data in the previous section, the most frequent cohesive errors made by the medium and high-level proficiency pre-service teachers are lexical cohesion, reference, ellipsis and conjunction. This is supported by other studies, whereby reference, conjunction and lexical cohesion posed the greatest difficulty for students (Ong, 2011). However, there were relatively few or no substitution or ellipsis errors made by the ESL pre-service teachers. This is to be expected as these two types of cohesive devices are rarely used in written text (Xu, 1992; Zhang, 2010).

However, the absence of these cohesive errors may not necessarily mean that the pre-service teachers have mastered these cohesive devices. It may even mean the opposite. This is because, due to the limitations of error analysis, learners' strategy of avoidance where learners tend to avoid using language features that are difficult for them is unaccounted for (Brown, 2007; Lightbown \& Spada, 2006). In Schachter's (1974) study with Persian, Arab, Chinese and Japanese students studying English, it was concluded that the students only made fewer errors in relative clauses because they were avoiding producing the language features that were difficult for them. Therefore, it is quite likely that medium-level proficiency pre-service teachers were unfamiliar with and did not know how to use ellipsis and substitution cohesion. Thus, they avoided producing any in their writing, and consequently affected the frequency and percentage of the error types obtained. Nevertheless, depending solely on error analysis, this cannot be proven either (Schachter, 1974). Furthermore, the non-avoidance of the cohesive devices does not necessarily mean accurate usage or application (Na, 2011). Although the high-level proficiency pre-service teachers attempted to use ellipsis cohesion in their writing, all occurrences were inaccurate and contributed to the number of errors made. However, the erroneous forms that were used suggested that pre-service teachers were exposed to ellipsis cohesion and were daring enough to attempt it, but had not mastered it well enough to use accurately in their writing.

\subsection{Implications}

From the discussion and analysis of the study's findings, it was found that one of the major weak points in the cohesive writing of the ESL pre-service teachers is collocation. The types of collocation errors that the ESL pre-service teachers made indicate that there is a severe lack of emphasis on collocation in their study of the language during teacher education. The phrasal verbs that take prepositions are extremely important to convey very specific meanings. It appears that students are either unaware or extremely careless in the area of collocation in writing.

Besides that, lexical repetition and references are also two areas of cohesion that the pre-service teachers made quite a number of errors in. The examples of errors collected from the data also suggest that pre-service teachersare careless in using these cohesive devices in writing, where they are unclear and unspecified, or completely unnecessary. Furthermore, the absence or lack of substitution and ellipsis errors may actually imply that pre-service teachers are unfamiliar with these cohesive devices and are avoiding them in writing. These cohesive devices, although not compulsory in writing, facilitate cohesion in writing and add to the style and variety of good quality writing. Such severe cohesive errors or cohesive avoidance in writing should be a cause for concern, especially since these are pre-service English teachers in their final year who are about to go out into the education field.

As in all post-error analysis phases, the remedial steps that come after the identification and description of errors are what is imperative to rectify the pre-service teachers' failures and improve on their language proficiency. Therefore, all these areas of cohesive devices: lexical cohesion, reference, conjunction, substitution and ellipsis, should be emphasized in the linguistic courses undertaken by the ESL pre-service teachers, especially in the area of collocation. The results of the study imply that the current focus on these topics in the English teacher education program's linguistic courses may be insufficient, and thus, more rigorous attention should be given to ensure that the pre-service English teachers are well-equipped in all aspects of cohesive writing.

In order to do so, a sense of awareness on this area of cohesion in writing needs to be fostered. Even in learning aspects of the productive language like cohesion in writing, pre-service teachers in teacher education programs are often exposed to theories with little realistic practice. Although theories have its place in teacher education, it cannot be theory alone. Instead, these programs should focus on organising and manipulating "sufficient suitable 
and realistic experiences" that cater to the needs of pre-service teachers to internalize what has been learnt (Korthagen, 2010, p. 104). With regards to cohesive devices in writing, pre-service teachers need to do more than just learn the theories, but to engage in more written practice and reflection to truly learn devices like ellipsis, substitution and collocation, and use them effectively and appropriately in writing.

Furthermore, the teaching of certain linguistic aspects in language education has typically been an individual learning affair. However, involving other pre-service teacher peers in collaborative practice may enhance the learning, as it is increasingly encouraged among student teachers (Dobber et al., 2012). In using literacy narratives in sharing their teaching experiences, teacher candidates were able to make meaning from their experiences, while also provide further insight to others' (Parker, 2010). This can be applied to writing experiences. Narrating their use of cohesive devices can help raise awareness to cohesion in their writing, as well as gain insight from others' shared experiences.

\subsection{Limitations}

Firstly, the researchers acknowledge that the study has a small sample, consisting of only 30 pre-service English teachers. This is, of course, an insufficient representation of the population of pre-service teachers in Malaysia. Nevertheless, the cohesive error analysis of the corpus obtained from this sample yielded 92 cohesive errors which were scrutinised, categorised and analysed closely; and thus, believed to be sufficient to reveal areas of weaknesses of the pre-service teachers and differences between high and medium-level proficiency pre-service English teachers.

In addition, limitations of the present study encompasses those of an error analysis study, whereby learners avoiding difficult structures that have not been mastered yet are not taken into account. Even after analysis, an absence of errors in a certain category type does not necessarily mean the aspect has been completely mastered. This certainly poses a problem, since both accurate usage and avoidance of aspects of uncertainty are lumped together. Despite that, errors that were identified indicated concrete evidence of the pre-service teachers' areas of weaknesses, which allows for further actions to be taken to improve on them.

\section{Conclusion}

The study found that pre-service English teachers as ESL learners in the Malaysian context do experience difficulty in the area of cohesion in writing. This is supported by other studies that have found similar areas of difficulty in cohesion by students, particularly lexical cohesion collocation, reference and conjunction. The results of the present study for Medium-level proficiency pre-service teachers reflected the same findings, but the High-level proficiency pre-service teachers differed in that they made more frequent errors in lexical cohesion collocation, ellipsis and reference. However, it was discussed that the absence or lack of errors in the error types of substitution and ellipsis may not necessarily mean that the pre-service teachers have mastered those cohesive devices due to the avoidance strategy that learners tend to have in producing language features that are difficult for them. This means that it is likely that the Medium-level proficiency pre-service teachers lacked mastery in those aspects as well despite producing no errors in those categories. On the other hand, the High-level proficiency pre-service teachers were daring enough to make attempts at using ellipsis cohesion, but occurrences of errors implied that they had not mastered it either. Therefore, all the 5 categories of cohesion, especially collocation in writing, need to be focused on and studied in depth in the linguistic courses undertaken by ESL pre-service teachers during their years in teacher education in order to improve their mastery of cohesive writing, and thus enable them to effectively teach and guide their future students.

\section{Acknowledgements}

The researchers would like to thank the ESL pre-service teachers from UKM who generously participated in the study.

\section{References}

Anon. (2003, May 7). Elevate writing instruction. USA Today, p. 4.

Benjamin, N. (2012, October 13). 25 more English teaching assistants for Malaysia in 2013. The Star Online. Retrieved from http://thestar.com.my/news/story.asp?file=/2012/10/13/nation/20121013150538\&sec=nation

Brown, H. D. (2007). Principles of language learning and teaching. New York: Pearson Longman.

Castro, C. D. (2004). Cohesion and the social construction of meaning in the essays of Filipino college students writing in L2 English. Asia Pacific Education Review, 5, 215-225.

Corder, S. P. (1967). The significance of learners' errors. International Review of Applied Linguistics, 9, 147-159. 
Crossley, S. A., \& McNamara, D. S. (2010a). Cohesion, coherence, and expert evaluations of writing proficiency. In Proceedings of the 32nd annual conference of the Cognitive Science Society (pp. 984-989).

Crossley, S. A., \& McNamara, D. S. (2010b). Predicting second language writing proficiency: The roles of cohesion and linguistic sophistication. Journal of Research in Reading, 1-21.

De Villez, R. (2003). Writing: Step by step. Dubuque, IA: Kendall Hunt.

Dobber, M., Akkerman, S. F., Verloop, N., \& Vermunt, J. D. (2012). Student teachers' collaborative research: Small-scale research projects during teacher education. Teaching and Teacher Education, 28, 609-617. http://dx.doi.org/10.1016/j.tate.2012.01.009

Glossary of Education. (2012). Pre-service teacher. Retrieved form http://www.education.com/definition/ preservice-teacher/

Grabe, W. (1985). Written discourse analysis. In R. B. Kaplan (Ed.), Annual Review of Applied Linguistics (Vol. 5, pp. 101-123). New York: Cambridge University.

Halliday, M. K., \& Hasan, R. (1976). Cohesion in English. London: Longman.

Hashemi, M., Azizinezhad, M., \& Dravishi, S. (2012). The investigation of collocational errors in university students' writing majoring in English. Procedia Social and Behavioral Sciences, 31, 555-558.

Hashim, A. (1999). Crosslinguistic influence in the written English of Malay undergraduates. Journal of Modern Languages, 12(1), 59-76.

Hinkel, E. (2003). Simplicity without elegance: Features of sentences in L1 and L2 academic texts. TESOL Quarterly, 37(2), 275-301.

Huang, X. (2005). Multilevel analysis of Chinese EFL learners' errors in their writing. CELEA Journal, 28(5), 24-32.

Jalaluddin, I., Yamat, H., \& Yunus, M. M. (2013). ESL writing self-efficacy: Contribution to ESL writing skills development. IOSR Journal of Research \& Method in Education, 2, 34-47.

Jalleh, J. (2012, September 26). Majority of teachers not proficient in English. The Star Online. Retrieved from http://thestar.com.my/news/story.asp?file=/2012/9/26/nation/12083360\&sec=nation

Kafes, H. (2010). Lexical cohesion: An issue only in the foreign language? English Language Teaching, 5(3), 83-94. http://dx.doi.org/10.5539/elt.v5n3p83

Korthagen, F. A. J. (2010). Situated learning theory and the pedagogy of teacher education: Towards an integrative view of teacher behaviour and teacher learning. Teaching and Teacher Education, 26, 98-106. http://dx.doi.org/10.1016/j.tate.2009.05.001

Kyriakides, L., Christoforou, C., \& Charalambous, C. Y. (2013). What matters for student learning outcomes: A meta-analysis of studies exploring factors of effective teaching. Teaching and Teacher Education, 36, 143-152. http://dx.doi.org/10.1016/j.tate.2013.07.010

Lightbown, P. M., \& Spada, N. (2006). How languages are learned. Oxford: Oxford University Press.

Liu, M., \& Braine, G. (2005). Cohesive features in argumentative writing produced by Chinese undergraduates. System, 33, 623-636.

Lowry, P. B., Curtis, A., \& Lowry, M. R. (2004). Building a taxonomy and nomenclature of collaborative writing to improve interdisciplinary research and practice. Journal of Business Communication, 41(1), 66-99.

McNamara, D. S., Crossley, S. A., \& McCarthy, P. M. (2010). Linguistic features of writing quality. Written Communication, 27(1), 57-86.

Na, Y. H. (2011). Cohesive devices in CMC texts produced by American and Korean EFL writers. Linguistic Research, 28(3), 743-771.

Nel, N., \& Müller, H. (2010). The impact of teachers' limited English proficiency on English second language learners in South African schools. South African Journal of Education, 30(4), 635-650.

Ong, J. (2011). Investigating the use of cohesive devices by Chinese EFL learners. The Asian EFL Journal Quarterly, 13(3), 42-65.

Parker, D. C. (2010). Writing and becoming [a teacher]: Teacher candidates' literacy narratives over four years. Teaching and Teacher Education, 26, 1249-1260. http://dx.doi.org/10.1016/j.tate.2010.03.002 
Sadeghi, K. (2009). Collocational differences between L1 and L2: Implications for EFL learners and teachers. TESL Canada Journal, 26(2), 100-124.

Sadighi, F., \& Heydari, P. (2012). Cohesion analysis of L2 writing: The case of Iranian undergraduate EFL learners. Mediterranean Journal of Social Sciences, 557-573.

Said, N. E. M., Yunus, M., Doring, L. K., Asmi, A., Aqilah, F., \& Kwan, L. S. L. (2013). Blogging to enhance writing skills: A survey of students' perception and attitude. Asian Social Science, 9(16), 95-101.

Schachter, J. (1974). An error in error analysis. Language learning, 24(2), 205-214.

Song, M., \& Xia, W. (2002). Combination of textual cohesive ties and textual teaching for the teaching of English writing. Foreign Language World, 6, 40-44.

Tangkiengsirisin, S. (2010). Promoting cohesion in EFL expository writing: A study of graduate students in Thailand. International Journal of Arts and Sciences, 3(16), 1-34.

$\mathrm{Xu}$, W. C. (1992). Cohesion, coherence and writing quality in Chinese college seniors writing (Unpublished master thesis). Zhongshan University, Guangzhou City, China.

Yunus, M. M., Salehi, H., \& Chen, C. (2012). Integrating social networking tools into ESL writing classroom: Strengths and weaknesses. English Language Teaching, 5(8), 42-48. http://dx.doi.org/10.5539/elt.v5n8p42

Yunus, M. M., Salehi, H., \& Nordin, N. (2012). ESL pre-service teachers' perceptions on the use of paragraph

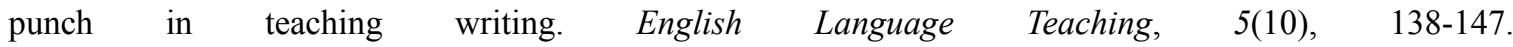
http://dx.doi.org/10.5539/elt.v5n10p138

Zhang, A. (2010). Use of cohesive ties in relation to the quality of compositions by Chinese college students. Journal of Cambridge Studies, 5(2-3), 78-86.

\section{Appendix A}

Cohesive errors made by individual students

*Cohesive errors are underlined, corrected in parentheses.

Respondent code: 01, 02...30

Proficiency Level: M-Medium, H-High

\begin{tabular}{lll}
\hline \multicolumn{2}{l}{ Erroneous sentences } & Category/Subcategory \\
\hline 01 & 1) The second night we stayed there, something happened. (On the second & Lexical/Collocation \\
$M$ & night) &
\end{tabular}

2) We were having fun with student's night performance when suddenly a girl screamed loudly and went berserk. (have fun doing sth/have fun with $\mathrm{sb)}$

3) A friend happened to know how to 'heal' this kind of sickness. They

Lexical/Collocation were talking in Tamil asking and wailing us to leave the campsite. (unspecified "they")

4) They were talking in Tamil asking and wailing us to leave the campsite. Lexical/Collocation (wailing is an intransitive verb)

5) Amazingly, another 3 more girls continued screaming and wailing like Lexical/Repetition crazy. (either another or more)

02 1) Thus, it is not wrong if I had dreamt myself to become a millionaire. (I Lexical/Collocation

$\mathrm{H}$ had dreamt of doing sth)

2) If I were a millionaire, I would be the happiest person in the world. By then, I can use the money to make a lot of my dreams to come true. (wrong usage of "by then")

3) By then, I can use the money to make a lot of my dreams to come true. Lexical/Collocation (make dreams $\varnothing$ come true)

4) If I were a millionaire, I will use the money and send my parents to have Conjunction a vacation in whatever places they like. (to) 
5) If I were a millionaire, I will use the money and send my parents to have a vacation in whatever places they like. (send sb on a vacation)

6) If I were a millionaire, I will use the money and send my parents to have a vacation in whatever places they like. ( $\varnothing$ wherever)

7) My parents have never been to travel to anywhere together. (to travel $\varnothing$ anywhere)

8) Hence it is my turn to enlighten their life if $\underline{I}$ am affordable to do that. Lexical/Collocation (sth is affordable, not sb)

9) This is also to prevent myself from being over spending. (prevent sb from doing sth)

10) If I were a millionaire, I would use a portion to start my own business to run a book shop. (either to start own business or run a book shop)

03 1) If I were a Millionaire, the first thing to do is I would travel around the

$\mathrm{M}$ world and be at the Seven Wonders creation in the world. (creation unnecessary)

2) If I were a Millionaire, the first thing to do is I would travel around the world and be at the Seven Wonders creation in the world. (of the world)

3) It is fascinating as how different people in certain cultures could be. (fascinating $\varnothing$ how sb/sth)

4)...the preserved human from hundred years ago. (hundreds of years ago)

5) And of course I will bring along my precious family to share my happiness. (bring sb/sth along)

6) After that I want to donate my huge sum of money for charity. (donate sth to, not for)

7) I want to provide health treatment there and I hope my money is enough to do all these. (unclear "there")

$04 \quad$ 1) I tried to say it out loud several times to call for any serious thought I

M ever had about it. (wrong usage of "call")

2) I tried to say it out loud several times to call for any serious thought I ever had about it. (unclear "it")

3) Yes, I dreamt of it, and might still do, but I think it is just as a fairy tale to me. (just sth, not just as sth)

4) We are brought up by them anyway. (grew up with sth)

5) All of us read fairy tales... Not to mention the "happily ever after" connotation it brings. (they bring)

6) We could be so carried away with the feeling that we almost forget that life is not as easy and sweet as in fairy tales. (carried away by sth)

7) We could be so carried away with the feeling that we almost forget that life is not as easy and sweet as in fairy tales. (inaccurate)

8) I would rather be a realistic person than keep on living in a world never exist. (in a world that does not exist)

9) Same goes to the idea about being a millionaire. (the same goes for $\mathrm{sb} / \mathrm{sth})$

10) Same goes to the idea about being a millionaire. (the idea of sb/doing sth)

05 1) If I were a millionaire, the first thing that I would do is to bring my

M whole family for Umrah. That would the best place for my family and I spending time together and doing 'ibadah'. (referring to umrah; the best
Lexical/Collocation

Lexical/Collocation

Lexical/Collocation

Lexical/Collocation

Lexical/Collocation

Lexical/Repetition

Lexical/Repetition

Lexical/Collocation

Lexical/Collocation

Lexical/Collocation

Lexical/Collocation

Lexical/Collocation

Reference/Demonstrative

Lexical/Collocation

Reference/Personal

Lexical/Collocation

Lexical/Collocation

Reference/Personal

Lexical/Collocation

Lexical/Synonymy

Conjunction

Lexical/Collocation

Lexical/Collocation

Lexical/Synonymy 
thing, not place)

2) If I have extra money, I would like to donate some to the unfortunate Lexical/Collocation people such as the orphans and the old folks. (less fortunate)

06 1) I always think of myself be in certain places like in the New York where Lexical/Repetition

$\mathrm{M}$ I can go shopping and experience new things.

2) I always think of myself be in certain places like in the New York where Lexical/Repetition I can go shopping and experience new things. (places like $\varnothing$ sth)

3) ....and I said to myself that one day I will go to this place and see it by my Reference/Demonstrative own eyes. (these places)

4) ....and I said to myself that one day I will go to this place and see it by my Lexical/Collocation own eyes. (see sth with own eyes)

5) ...I know the feeling when you are in need but there is nobody is there...

Lexical/Repetition

6) ...where there are a lot of beggars who ask money so that they can Lexical/Collocation continue their life. (ask for sth)

7) ...where there are a lot of beggars who ask money so that they can Lexical/Collocation continue their life. (continue on with their life)

07 1) At the same time, she could not help feeling sorry to her boyfriend who Lexical/Collocation

$\mathrm{M} \quad$ was feeling unwell. (feel sorry for $\mathrm{sb}$ )

08 1) Just like when Beyonce sings "If I were a boy". Well, she can't. (she Ellipsis/Nominal $\mathrm{H}$ isn't)

2) I have this habit of spending every bit of cash I have when I go for a Lexical/Collocation shopping spree. (go on a shopping spree)

3) To make it worse, my life motto is "Money is meant to be spent". (to Lexical/Collocation make things worse)

09 1) ... and I had to play a character name Paul whose a kid at the age of $7 . \quad$ Reference/Personal

$\mathrm{M}$ (who is)

10 1) Little did I know, my 'hose' was almost full filled with urine or should I Lexical/Repetition

M say alcohol that I had the night before. (either full or filled)

2) The moment I found the washroom situated near at a hidden corner... Lexical/Repetition (either near or at)

3) I quickly flashed in the toilet and discharge myself... (relieved)

Lexical/Collocation

11 1) ...which is an NGO to help the one who really in need. (those)

$M \quad 2)$ They will sponsor the poor children in all over the world...

Reference/Demonstrative

3) They will sponsor the poor children in all over the world to let them have a chance to learn, to study, and improve them into a better life. (themselves)

4) ....and improve them into a better life. (for)

Lexical/Repetition

Reference/Personal

5) Besides from that, I will use half of the half million to backpack around the world. (besides that)

6) I wish I can walk around the world, work there, live there for few months, enjoy the leisure life, try a different life of what I have now. (wrong usage)

7) I wish I can walk around the world, work there, live there for few months, enjoy the leisure life, try a different life of what I have now. (different from/to/than)

8) Maybe this is not a realistic idea since I don't have any basic knowledge on investment but I still want to try it. (knowledge in)

Lexical/Collocation

Lexical/Collocation

Reference/Demonstrative

Lexical/Collocation

Lexical/Collocation 
12 1) ...I bet every single person in this world will raise their hands, so do I. Ellipsis/Verbal

$\mathrm{H} \quad$ (as will I)

2) I wish to set my foot in all the wonders of the ancient world and current Lexical/Collocation century. (set $\varnothing$ foot)

3) I would love to donate to charity, perhaps could own a charity and

Reference/Personal supports those that couldn't afford their education and medical expenses. (who)

4) Helping those in need will give me an utmost satisfaction. (to give $\varnothing$ Lexical/Collocation utmost satisfaction)

$13-$

$\mathrm{H}$

$14-$

$\mathrm{H}$

15 1) Suddenly, a student fell over the floor because the floor was wet and Lexical/Collocation

M slippery. (fell onto sth)

2) We burst into laughs and as usual, I was the one who laughs louder. Lexical/Collocation (burst into laughter)

3) I slipped over the floor and my foods spilled on my uniform! (slipped on Lexical/Collocation sth)

4) I slipped over the floor and my foods spilled on my uniform! (spilled Lexical/Collocation onto sth)

5) Everybody burst into laughs at me. (either burst into laughter, or laughed Lexical/Repetition at me)

16 1) Firstly, I would sponsor my whole family on a Europe tour! (sponsor Lexical/Collocation

$\mathrm{H} \quad \mathrm{sb} / \mathrm{sth}$ for)

17 1) ...where not only I can play with my family and friends, but also I can Lexical/Repetition

M watch people come and play my most favourite sport.

18 1) This is because I know how it feels like to be dependable on others all Lexical/Collocation

$\mathrm{H}$ the time as at the moment, I am depending on my father to send me to the places that I want to go, and it is really annoying and embarrassing. (dependent)

2) Besides, I would like to invest the money on myself and my family so that I will have my own savings in the future. (besides that)

3) Besides, I would like to invest the money on myself and my family so Lexical/Collocation that I will have my own savings in the future. (invest in sth)

19 1) Who in the world does not want a lot amount of money? (a large Lexical/Collocation M amount)

2) ...the first thing that I will do is to invest the money on my family and Lexical/Collocation myself. (invest in sth)

3) I would provide their needs as well as the facilities. (provide for)

Lexical/Collocation

4) I feel a great pain whenever I see them especially the children. Most of Reference/Personal them are not able to afford education for their children. (incorrect "them")

20 1) So, we picked up a pink blouse which had a 40 percent discount tag on Lexical/Collocation

$\mathrm{M}$ it. (held up)

2) ...I took the opportunity to buy a very special jeans for my sister... (pair Lexical/Collocation of jeans)

3) After paying the items, we decided to go to the fourth floor. (paying for) Lexical/Collocation

21 1) One of four, I had the opportunity of a lifetime to visit Mexico for three Ellipsis/Nominal 
$\mathrm{H}$ weeks. (unclear)

22 1) It took more than 12 hours and I just got paid for rm400 per month. (paid Lexical/Collocation

M RM400, not paid for)

2) Since that was my first time of working, so I did not really mind of Lexical/Collocation having only one hour break in the afternoon. (first time doing sth)

3) Since that was my first time of working, so I did not really mind of Lexical/Collocation having only one hour break in the afternoon. (did not mind doing sth)

4) I still remember the incident was happened after my lunch break. Lexical/Repetition $23-$

24 1) To play my part in society, I would use a fair bit of my wealth to set up Reference/Demonstrative

$\mathrm{H} \quad$ centres in the city where people can come for help in terms of shelter. This centre caters to the homeless... (these centres)

$25-$

M

26 1) ...mini car which he would use to travel from one place in his castle from Lexical/Collocation

$\mathrm{H}$ another. (from one place to another, not from)

27 1) It is also important to get involve into charity, as there are many Lexical/Collocation

M unfortunate people who do not have the luxury to enjoy a comfortable life. (get involved in sth)

28 1) I had enrolled myself taking a short course in a skill-based learning Lexical/Collocation

M center somewhere near the town. (enrolled in sth)

2) They were all had been so nice to me.

Lexical/Repetition

3) The first day I reached the hostel, I was getting into knowing my new Lexical/Collocation friends and roommates. (getting to know)

29 1) My most embarrassing experience happened to me not long time ago. Lexical/Collocation M (not long ago)

2) One day, my father asked me to accompany him to the hypermarket to Lexical/Collocation shop some groceries. (to shop for sth)

3) After that, we have to queue in such a long line at the counter. (queue Lexical/Collocation up)

4) Being tired waiting for so long, my father left me and said he will wait Lexical/Collocation for me in the car. (tired of waiting)

$30-$

$\mathrm{H}$

\section{Appendix B}

Cohesive errors made by Medium-level proficiency students

*Cohesive errors are underlined, corrected in parentheses.

\begin{tabular}{lll}
\hline Categories & Subcategories & Erroneous sentences \\
\hline Reference & Personal & 1) A friend happened to know how to 'heal' this kind of sickness. They \\
were talking in Tamil asking and wailing us to leave the campsite. \\
(unspecified "they") \\
2) I tried to say it out loud several times to call for any serious thought I \\
ever had about it. (unclear "it") \\
3) All of us read fairy tales... Not to mention the "happily ever after" \\
connotation it brings. (they bring) \\
4) ... and I had to play a character name Paul whose a kid at the age of 7.
\end{tabular}


(who is)

5) They will sponsor the poor children in all over the world to let them have a chance to learn, to study, and improve them into a better life. (themselves)

6) I feel a great pain whenever I see them especially the children. Most of them are not able to afford education for their children. (incorrect "them")

Demonstrative 1) I want to provide health treatment there and I hope my money is enough to do all these. (unclear "there")

2) ....and I said to myself that one day I will go to this place and see it by my own eyes. (these places)

3) ...which is an NGO to help the one who really in need? (those)

4) I wish I can walk around the world, work there, live there for few months, enjoy the leisure life, try a different life of what I have now. (wrong usage)

Comparative

\begin{tabular}{llr}
\hline Substitution & Nominal & - \\
& Verbal & - \\
& Clausal & - \\
\hline Ellipsis & Nominal & - \\
& Verbal & - \\
& Clausal & \\
&
\end{tabular}

Conjunction

1) I would rather be a realistic person than keep on living in a world never exist. (in a world that does not exist)

\begin{tabular}{ll}
\hline Lexical & Repetition \\
cohesion &
\end{tabular}

1) Amazingly, another 3 more girls continued screaming and wailing like crazy. (either another or more)

2) If I were a Millionaire, the first thing to do is I would travel around the world and be at the Seven Wonders creation in the world. (creation unnecessary)

3) I always think of myself be in certain places like in the New York where I can go shopping and experience new things.

4) I always think of myself be in certain places like in the New York where I can go shopping and experience new things. (places like $\varnothing$ sth)

5) ...I know the feeling when you are in need but there is nobody $\underline{\text { is }}$ there...

6) Little did I know, my 'hose' was almost full filled with urine or should I say alcohol that I had the night before. (either full or filled)

7) The moment I found the washroom situated near at a hidden corner... (either near or at)

8) They will sponsor the poor children in all over the world...

9) ...where not only I can play with my family and friends, but also I can watch people come and play my most favourite sport.

10) I still remember the incident was happened after my lunch break.

11) They were all had been so nice to me.

Synonymy 1) We could be so carried away with the feeling that we almost forget that life is not as easy and sweet as in fairy tales. (inaccurate)

2) If I were a millionaire, the first thing that I would do is to bring my whole family for Umrah. That would the best place for my family and I spending time together and doing 'ibadah'. (referring to umrah; the best 
thing, not place)

Antonymy

Hyponymy

Collocation
1) The second night we stayed there, something happened. (On the second night)

2) We were having fun with student's night performance when suddenly a girl screamed loudly and went berserk. (have fun doing sth/have fun with $\mathrm{sb)}$

3) They were talking in Tamil asking and wailing us to leave the campsite. (wailing is an intransitive verb)

4) If I were a Millionaire, the first thing to do is I would travel around the world and be at the Seven Wonders creation in the world. (of the world)

5) It is fascinating as how different people in certain cultures could be. (fascinating $\varnothing$ how sb/sth)

6) ...the preserved human from hundred years ago. (hundreds of years ago)

7) And of course I will bring along my precious family to share my happiness. (bring sb/sth along)

8) After that I want to donate my huge sum of money for charity. (donate sth to, not for)

9) I tried to say it out loud several times to call for any serious thought I ever had about it. (wrong usage of "call")

10) Yes, I dreamt of it, and might still do, but I think it is just as a fairy tale to me. (just sth, not just as sth)

11) We are brought up by them anyway. (grew up with sth)

12) We could be so carried away with the feeling that we almost forget that life is not as easy and sweet as in fairy tales. (carried away by sth)

13) Same goes to the idea about being a millionaire. (the same goes for $\mathrm{sb} / \mathrm{sth})$

14) Same goes to the idea about being a millionaire. (the idea of sb/doing sth)

15) If I have extra money, I would like to donate some to the unfortunate people such as the orphans and the old folks. (less fortunate)

16) ....and I said to myself that one day I will go to this place and see it by my own eyes. (see sth with own eyes)

17) ...where there are a lot of beggars who ask money so that they can continue their life. (ask for sth)

18) ...where there are a lot of beggars who ask money so that they can continue their life. (continue on with their life)

19) At the same time, she could not help feeling sorry to her boyfriend who was feeling unwell. (feel sorry for sb)

20) I quickly flashed in the toilet and discharge myself... (relieved)

21) ....and improve them into a better life. (for)

22) Besides from that, I will use half of the half million to backpack around the world. (besides that)

23) I wish I can walk around the world, work there, live there for few months, enjoy the leisure life, try a different life of what I have now. 
(different from/to/than)

24) Maybe this is not a realistic idea since I don't have any basic knowledge on investment but I still want to try it. (knowledge in)

25) Suddenly, a student fell over the floor because the floor was wet and slippery. (fell onto sth)

26) We burst into laughs and as usual, I was the one who laughs louder. (burst into laughter)

27) I slipped over the floor and my foods spilled on my uniform! (slipped on sth)

28) I slipped over the floor and my foods spilled on my uniform! (spilled onto sth)

29) Who in the world does not want a lot amount of money? (a large amount)

30) ...the first thing that I will do is to invest the money on my family and myself. (invest in sth)

31) I would provide their needs as well as the facilities. (provide for)

32) So, we picked up a pink blouse which had a 40 percent discount tag on it. (held up)

33) ...I took the opportunity to buy a very special jeans for my sister... (pair of jeans)

34) After paying the items, we decided to go to the fourth floor. (paying for)

35) It took more than 12 hours and I just got paid for rm400 per month. (paid RM400, not paid for)

36) Since that was my first time of working, so I did not really mind of having only one hour break in the afternoon. (first time doing sth)

37) Since that was my first time of working, so I did not really mind of having only one hour break in the afternoon. (did not mind doing sth)

38) It is also important to get involve into charity, as there are many unfortunate people who do not have the luxury to enjoy a comfortable life. (get involved in sth)

39) I had enrolled myself taking a short course in a skill-based learning center somewhere near the town. (enrolled in sth)

40) The first day I reached the hostel, I was getting into knowing my new friends and roommates. (getting to know)

41) My most embarrassing experience happened to me not long time ago. (not long ago)

42) One day, my father asked me to accompany him to the hypermarket to shop some groceries. (to shop for sth)

43) After that, we have to queue in such a long line at the counter. (queue up)

44) Being tired waiting for so long, my father left me and said he will wait for me in the car. (tired of waiting) 


\section{Appendix C}

Cohesive errors made by High-level proficiency students

${ }^{*}$ Cohesive errors are underlined, corrected in parentheses.

\begin{tabular}{lll}
\hline Categories & Subcategories & Erroneous sentences \\
\hline Reference & Personal & $\begin{array}{l}\text { 1) I would love to donate to charity, perhaps could own a charity and } \\
\text { supports those that couldn't afford their education and medical expenses. } \\
\text { (who) }\end{array}$
\end{tabular}

Demonstrative 2) To play my part in society, I would use a fair bit of my wealth to set up centres in the city where people can come for help in terms of shelter. This centre caters to the homeless... (these centres)

\begin{tabular}{lll} 
& Comparative & - \\
\hline Substitution & Nominal & - \\
& Verbal & - \\
& Clausal & -
\end{tabular}

\begin{tabular}{ll}
\hline Ellipsis & 1) Just like when Beyonce sings “If I were a boy". Well, she can't. (she \\
isn't) & 2) One of four, I had the opportunity of a lifetime to visit Mexico for three \\
weeks. (unclear)
\end{tabular}

Verbal 1) ...I bet every single person in this world will raise their hands, so do I. (as will I)

\begin{tabular}{lll} 
& Clausal & (as will I) \\
\hline Conjunction & & 1) If I were a millionaire, I will use the money and send my parents to have \\
a vacation in whatever places they like. (to)
\end{tabular}


10) To make it worse, my life motto is "Money is meant to be spent". (to make things worse)

11) I wish to set my foot in all the wonders of the ancient world and current century. (set $\varnothing$ foot)

12) Helping those in need will give me an utmost satisfaction. (to give $\varnothing$ utmost satisfaction)

13) Firstly, I would sponsor my whole family on a Europe tour! (sponsor $\mathrm{sb} / \mathrm{sth}$ for)

14) This is because I know how it feels like to be dependable on others all the time as at the moment, I am depending on my father to send me to the places that I want to go, and it is really annoying and embarrassing. (dependent)

15) Besides, I would like to invest the money on myself and my family so that I will have my own savings in the future. (besides that)

16) Besides, I would like to invest the money on myself and my family so that I will have my own savings in the future. (invest in sth)

17) ...mini car which he would use to travel from one place in his castle from another. (from one place to another, not from)

\section{Copyrights}

Copyright for this article is retained by the author(s), with first publication rights granted to the journal.

This is an open-access article distributed under the terms and conditions of the Creative Commons Attribution license (http://creativecommons.org/licenses/by/3.0/). 